Fabian Schmid, Lina Taube, Jenny Rieck, Frank Behrendt

\title{
Electrification of waste collection vehicles: Techno-economic analysis based on an energy demand simulation using real-life operational data
}

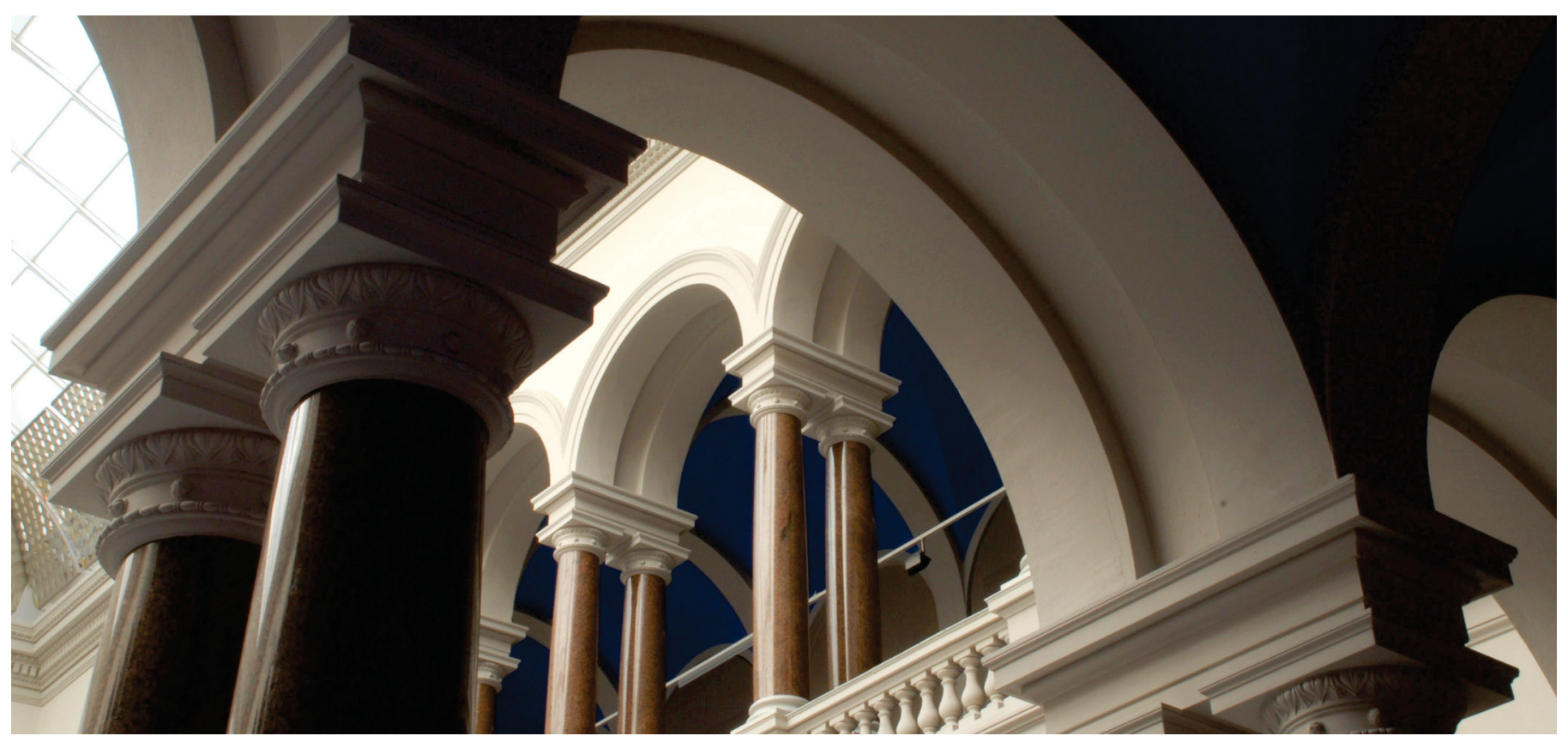

Schmid, F., Taube, L., Rieck, J., \& Behrendt, F. (2020). Electrification of waste collection vehicles:

Techno-economic analysis based on an energy demand simulation using real-life operational data. IEEE

Transactions on Transportation Electrification. https://doi.org/10.1109/tte.2020.3031072 


\title{
Electrification of waste collection vehicles:
}

\section{Techno-economic analysis based on an energy demand simulation using real-life operational data}

\author{
Authors: Fabian Schmid ${ }^{\mathrm{a}, \mathrm{b}}$, Lina Taube ${ }^{\mathrm{a}}$, Jenny Rieck ${ }^{\mathrm{a}}$, Frank Behrendt ${ }^{\mathrm{a}}$ \\ a Technical University of Berlin, Chair of Energy Process Engineering and Conversion Technologies of Renewable \\ Energies, Seestrasse 13, 13353 Berlin, Germany \\ ${ }^{\mathrm{b}}$ Corresponding author. \\ Fabian Schmid, fabian.schmid@tu-berlin.de \\ Lina Taube, lina.taube@tu-berlin.de \\ Jenny Rieck, jenny.rieck@tu-berlin.de \\ Frank Behrendt, frank.behrendt@tu-berlin.de \\ Authors are not IEEE members. \\ This paper has not been presented at a conference or submitted elsewhere previously.
}

\section{Keywords:}

- Electrification of waste collection vehicles

- Energy demand simulation

- Route synthetization

- Total cost of ownership

- Well-to-Wheel emission costs

\begin{abstract}
:
Waste transport plays an important role in the decarbonization of the transport sector. In this paper diesel-powered $(\mathrm{dWCV})$ and electric waste collections vehicles (eWCV) and their operation are analysed regarding energy demand and total cost of ownership (TCO) integrating Well-to-Wheel emission costs. Further, an open-source simulation tool with a route synthetization approach is presented using extensive real-life operational data of five different route types. Determined WCV energy demand varies greatly between vehicle topologies and analysed route types. eWCV show a mean distance-specific energy demand of $1.85 \mathrm{kWh} \cdot \mathrm{km}^{-1}$, while values for $\mathrm{dWCV}$ increase to $5.43 \mathrm{kWh} \cdot \mathrm{km}^{-1}$ respectively. The factors route distance and number of waste containers collected show the highest influence on results. Therefore, battery capacity should be sized according to specific route types. eWCV show higher TCO than dWCV under current economic constraints but fuel price level and annual vehicle mileage show a high influence on economic feasibility. Taking the planned emissions price mechanism of the German Government into account, economic scenarios could be identified, which make eWCV advantageous yet in 2021. In technical terms, there is nothing to stop for the electrification of $\mathrm{WCV}$, and with suitable political instruments eWCV could become profitable in the short-term.
\end{abstract}

\section{Introduction}

With the introduction of its Energy Concept (Energiekonzept) the German Government aims to achieve an environmentally friendly, reliable and affordable energy supply by 2050 [1]. This includes the planned energy transition (Energiewende) with the expansion of renewable energies and transition of the mobility sector, in particular the development and integration of e-mobility. Traffic caused by the service sector is of crucial importance for the decarbonization of the transport sector. Public transport as well as supply and waste transport are particularly qualified for an electrification due to their well-planned route typology. According to the Federal Motor Vehicle Transport Authority (Kraftfahrt-Bundesamt, KBA), 13,301 waste collection vehicles (WCV) had been approved in Germany by January 1, 2018 [2]. The Berlin municipal waste management company (Berliner Stadtreinigung, BSR) is in the process of decarbonizing its vehicle fleet by replacing dieselpowered WCV (dWCV) with fully battery electric powered WCF (eWCV), with its first pilot eWCV in testing since 2019 [3, 4]. Other municipal waste management companies are taking similar measures, e.g. in the city of Vienna or Gothenburg $[5,6]$.

For the assessment of new vehicle drive systems such as eWCV, an energy demand simulation can give 
detailed information on the fuel consumption and its influencing parameters as well as the feasibility and possible constraints of new topologies. This type of simulation is based on detailed models of the vehicle drive system, vehicle hydraulic system components for compacting and lifting of waste and the vehicle route profile, which can be determined using GPS data tracking or synthetic approaches. Energy demand of $\mathrm{WCV}$ is also required for the analysis of the economic aspects of such new systems. Here, the total cost of ownership (TCO) is a widely used approach that takes into account all costs that occur during a vehicle's lifetime.

In general, WCV and waste collection have not been simulated to a great extent. This is mainly because deterministic models are sufficiently accurate to plan WCV operation [7]. But they fall short for the simulation of new vehicle topologies such as the electrification of drivetrains or hydraulic system components. During the mid-90's, several studies were published by Everett et al. concerning the simulation of WCV and waste collection routes, which considered the influence of collection time and journey time $[8,9,10]$. As a result, Wilson and Baetz conclude that several variables are necessary for an accurate simulation, e. g. the distance between collection stops and towards the waste treatment facility as well as the amount of waste collected. They also mention the influence of the nature of the waste collection area regarding population density and building structure as well as of the respective waste collection policy and management. The latter include for example service frequency, work rules or vehicle capacity and, if given can be considered within models to achieve a high accuracy [7]. Therefore, Wilson and Baetz introduce a model that uses derived probability distributions to estimate the necessary time to service a route with given parameters. The model does not give any information on energy consumption [7]. Sonesson published a model to calculate service time as well as fuel consumption with the objective to be as general as possible. Thereby, various service areas with different numbers of stops and varying distance between the stops can be considered [11]. Larsen et al. also estimated the diesel consumption for different area types and found a high variety connected to the respective area and the amount of waste collected [12]. Nguyen and Wilson use GPS tracking to estimate the diesel consumption of WCV, but the changing amount of waste that needs to be transported is not considered [13].

Hybrid options for commercial vehicles have been discussed since the beginning of the 21 st century, with the overall objective of increasing fuel usage efficiency. Wu et al. introduced power management strategies for hybrid delivery trucks that use recuperated braking energy stored in a hydraulic accumulator. According to them this recuperation can increase fuel efficiency by more than $25 \%$ [14]. The concept of hybrid hydraulic vehicles has been pursued by Bender in several studies. Bender et al. developed a method to predict drive cycles, which can be used to optimise the usage of recuperated energy $[15,16]$. This was developed further for application to WCV in [17], using GPS and the data given by the standard vehicle controller area network bus. In all articles mentioned above detailed vehicle models are not given. While hybrid hydraulic systems for WCV do not seem to be considered further, the idea of energy recuperation has been preserved. Together with $\mathrm{CO}_{2}$ reduction efforts, this led to the development of hybrid electric WCV. This technology uses a battery to either operate just the hydraulic of the WCV body, or both hydraulic and vehicle drive [18, 19]. According to an investigation of an electric $18 \mathrm{t}$ truck by the ETH Zurich and IWF, up to $100 \%$ of braking in urban traffic can be performed by recuperation [20]. Due to the frequent starts and stops during the operation, WCV are very suitable for the recuperation of braking energy [21].

Until now, only few studies have been published that examine fully electrified WCV. At the research campus Mobility2Grid, an overall concept for the electrification of public buses and waste disposal traffic has been developed [22]. As part of this initiative, Gräbener developed and evaluated the options for electrification of WCV as an example for service sector vehicles [21]. However, both, the report and the dissertation, do not include a simulation of the vehicle behaviour in daily operation. Ewert et al. analysed the energy consumption of eWCV in Berlin using a multi-agent-based simulation [23]. An energy demand simulation is not presented in detail in the paper. Nagel et al. modelled waste collection by eWCV using a synthetic waste collection calendar but only assumed mean energy demand values without conducting any detailed simulation [24]. Erdinç et al. conducted an energy demand simulation of a $16 \mathrm{t}$ eWCV in Istanbul, but only for a comparably short distance of $7 \mathrm{~km}$ and 75 waste containers [25].

Even more scarce than detailed and open-source energy demand simulations of eWCV are economic assessments of such vehicles. Due to their new market integration, investment costs for eWCV are not yet published in list prices. Costs assumptions lie in the range of $400,000 €$ to $600,000 €$ for $\mathrm{eWCV}$ and $200,000 €$ to $250,000 €$ for dWCV [26, 27, 28, 29]. Ewert et al. determined the TCO of a dWCV and eWCV fleet in Berlin, stating that an electrification of the WCV fleet increases the TCO by $16-30 \%$. This shows the importance of further research in economically viable options for real-life implementation of eWCV.

The focus of this paper is the development of an opensource energy demand simulation for dWCV and eWCV, which includes a route synthetization using real-life operational data provided by a waste 
management company situated in Berlin, Germany ${ }^{1}$. Different route types with varying collection areas are considered. The total and specific energy demand of $\mathrm{dWCV}$ and $\mathrm{eWCV}$, as well as the influence of route type on eWCV energy demand is analysed. A TCO analysis takes current economic constraints into account and identifies possible pathways under consideration of the planned emissions price mechanism of the German Federal Government to make eWCV economically profitable. Therewith, our work brings following major contributions for the simulation and determination of the energy demand in daily operation and TCO of electric- and diesel-driven waste collection vehicles:

- Detailed energy demand simulation connected with a route synthetization approach, which makes it possible to forecast energy demand of diesel- and electric-driven waste collection vehicles.

- Innovative combination of energy demand and TCO calculation taking emission price mechanisms into account.

- Analysis of 387 real-life operation tours to point out possible electrification pathways of waste transport vehicles.

- Open-source concept of the developed simulation tool and its sharing via a freeware platform.

The current paper builds on the experiences made in the study 'Netzdienliche Integration hybrider Entsorgungsfahrzeuge' (Grid-beneficial Integration of Hybrid Waste Collection Vehicles).

\section{Methodology}

The methodology section presents implemented models of the energy demand simulation, the route synthetization and used equations for the TCO calculation.

The developed energy demand simulation including route synthetization and the route optimization is published under the Creative Commons AttributionShareAlike 4.0 International License and can be downloaded from GitHub ${ }^{2,3}$.

\section{$2.1 \quad$ Energy demand simulation}

The energy demand of an eWCV and the reference $\mathrm{dWCV}$ is modelled through a power flow simulation with a resolution of one second. Due to short computing times and low complexity requirements of such kind of models, the methodology of backward simulation is used. Therefore, a model for vehicle driving resistance, drivetrain and body and, in the case of an eWCV, an additional model for battery, battery management and charging infrastructure is developed. The vehicle route model provides speed, acceleration and duty cycle information and is based on real-life operational data from a waste management company.

\section{Driving resistance model}

The necessary drive power is determined using the driving resistance model, which is based on following equations $[30,31,21]$ :

$$
\begin{aligned}
& F_{\text {air }}(t)=\frac{1}{2} \cdot \rho \cdot A \cdot c_{d} \cdot v(t)^{2} \\
& F_{\text {roll }}(t)=c_{\text {rot }} \cdot m_{v}(t) \cdot g \cdot c_{r} \cdot \cos (\text { alpha }) \\
& F_{\text {slope }}(t)=c_{\text {rot }} \cdot m_{v}(t) \cdot g \cdot \sin (\text { alpha }) \\
& F_{\text {acceleration }}(t)=c_{\text {rot }} \cdot m_{v}(t) \cdot a \\
& P_{\text {drive }}(t)=\left(F_{\text {air }}(t)+\right. \\
& +F_{\text {roll }}(t)+F_{\text {slope }}(t) \\
& \left.\quad+F_{\text {acceleration }}(t)\right) \cdot v(t)
\end{aligned}
$$

where $F_{\text {air }}$ is the aerodynamic drag force, $F_{\text {roll }}$ is the rolling friction force, $F_{\text {slope }}$ is the hill climbing force, $F_{\text {acceleration }}$ is the acceleration resistance force, $\rho$ is the air density $\left[\mathrm{kg} \cdot \mathrm{m}^{-3}\right], A$ is the vehicle front surface area $\left[\mathrm{m}^{2}\right], c_{d}$ is the drag coefficient, $v$ is the vehicle speed $\left[\mathrm{m} \cdot \mathrm{s}^{-1}\right], c_{\text {rot }}$ is the coefficient of rotating masses, $m_{v}$ is the vehicle cumulated mass [kg], $g$ is the gravity of earth $\left[\mathrm{m} \cdot \mathrm{s}^{-2}\right], c_{r}$ is the rolling resistance coefficient, alpha the road slope $\left[{ }^{\circ}\right], a$ the vehicle acceleration in $\left[\mathrm{m} \cdot \mathrm{s}^{-2}\right], P_{\text {drive }}$ the vehicle mechanical power demand [W] and $t$ the timestep.

\section{Drivetrain model}

The vehicle motor input power is calculated with a simple drivetrain model, consisting of static efficiencies of all drivetrain components of the eWCV or dWCV. The electric motor can act additionally as a generator, which converts the mechanical braking energy into electrical energy according to the braking force recovery (recuperation). Braking is performed using the resistance of the generator instead of the conventional wheel brakes. For the definition of potential recuperation energy of an eWCV in the case of negative mechanical power, a generator mode is considered as well [20]. The drivetrain model is defined by the following equations:

$$
\begin{aligned}
& \eta_{\text {drivetrain }}=\eta_{\text {traction, } \text { motor } / \text { generator }} \cdot \eta_{\text {transmission }} \\
& \text { - } \eta_{\text {converter }} \\
& P_{\text {traction,motor }}(t)=\frac{P_{\text {drive }}(t)}{\eta_{\text {drivetrain }}} \quad ; \text { for } P_{\text {drive }}(t) \geq 0 \\
& P_{\text {traction,generator }}(t)=P_{\text {drive }}(t) \\
& \text { - } \eta_{\text {drivetrain }} \quad ; \text { for } P_{\text {drive }}(t)<0
\end{aligned}
$$

where $\eta_{\text {drivetrain }}$ is the total drivetrain efficiency, $\eta_{\text {traction,motor/generator }}$ the motor efficiency and in

\footnotetext{
1 Data collected in the study 'Grid-beneficial Integration of Hybrid Waste Collection Vehicles'.

https://github.com/fabmid/Refuse-Collection-Vehicle-Energy-DemandSimulation

${ }^{3}$ https://github.com/fabmid/Refuse-Collection-Vehicle-Route-Optimization
} 
case of an electric motor the generator efficiency, $\eta_{\text {transmission }}$ the efficiency of transmission, $\eta_{\text {converter }}$ the DC-DC converter efficiency for the eWCV, $P_{\text {traction,motor }}$ the traction motor input power [W], $P_{\text {traction,generator }}$ the generator electric output power of the traction motor $[\mathrm{W}]$ and $t$ the timestep.

\section{Body model}

There is a great variety of WCV body types, of which the majority are rear-loading systems. Rear-loaders with press plate system are currently used predominantly in the Berlin area. The modeling of the body system is therefore limited to such a system.

For each waste collection stop of the vehicle a duty cycle is considered that defines the power by the body system for lifting and compacting purpose. For simplification and due to lack of real-life data, a static energy demand per duty cycle and waste container of 90 Wh with a mean body input power and a mean body efficiency (compare Table 1) is defined. This assumption is based on the obtained mean values of a detailed study of the efficiency and energy demand of a press plate system using real-life data of 524 duty cycles given by Wysocki et al. in [32]. Authors present a detailed statistical analysis with energy demand, power and efficiency for the lifting and compacting process. Further Sandkühler et al. state that the mean power output lies at $10 \mathrm{~kW}$ and is highly dependent on the working style of the refuse collector [18]. For the present study no differentiation of container sizes and the mass of compacted waste is implemented. We neglect efficiency and power differences between lifting and compacting phase, and possible improvements gained through new development of full electric body systems. The body model is defined by the following equation:

$$
P_{\text {body }}(t)=n_{\text {waste container }} \cdot \frac{P_{\text {body,mean }}}{\eta_{\text {body,mean }}}
$$

where $P_{\text {body }}(t)$ is the body input power for lifting and compacting purpose $[\mathrm{W}], P_{b o d y, m e a n}$ is the static mean body output power, $\eta_{\text {body,mean }}$ is the mean body efficiency, $n_{\text {waste container }}$ is the number of collected container per stop (which is equal to the number of duty cycles per stop), and $t$ the timestep.

This leads to the definition of the overall power demand per time step of the eWCV and dWCV:

$$
\begin{gathered}
P_{d W C V, \text { in }}(t)=P_{\text {traction,motor }}(t)+P_{\text {body }}(t) \\
+P_{\text {auxiliaries }} \\
P_{\text {eWCV,in }}(t)=P_{\text {traction,motor }}(t)-P_{\text {traction,generator }}(t) \\
+P_{\text {body }}(t)+P_{\text {auxiliaries }}
\end{gathered}
$$

where $P_{d W C V \text {,in }}$ is the power demand of the dWCV [W] covered by the fuel input, $P_{e W C V, \text { in }}$ is the power demand of the eWCV [W] covered by the battery, $P_{\text {auxiliaries }}$ is the static power demand of auxiliary components (such as heating / cooling or light) [W] and $t$ the timestep

Table 1 gives an overview of the parameter assumptions made for the driving resistance, drivetrain and body model.

\section{Battery}

For the eWCV, the vehicle power demand is supplied through the battery system. An empirical lithium-ion battery model has been adapted for the present case. It defines:

- Dissipation of charging and discharging process

- $\quad$ State of Charge (SoC)

- Charging and discharging limits

The dissipation is modelled through a stationary equivalent circuit model, taking into account the power dependency. The SoC model follows an off-line

\begin{tabular}{|c|c|c|c|c|c|}
\hline Parameter & Symbol & Unit & dWCV & eWCV & Source \\
\hline Drag coefficient & $c_{d}$ & [1] & 0.63 & 0.63 & [30] \\
\hline Rolling resistance coefficient & $c_{r}$ & [1] & 0.007 & 0.007 & {$[30]$} \\
\hline Road slope & $\alpha$ & {$\left[{ }^{\circ}\right]$} & 0.0 & 0.0 & \\
\hline Coefficient of rotating masses & $c_{\text {rot }}$ & {$[1]$} & 1.10 & 1.10 & {$[33]$} \\
\hline Vehicle weight (empty/full) & $m$ & {$[\mathrm{~kg}]$} & $15.25 / 26.0$ & $17.25 / 26.0$ & [34] \\
\hline Vehicle front area & $A$ & {$\left[\mathrm{~m}^{2}\right]$} & 8.58 & 8.58 & [19] \\
\hline Traction motor efficiency & $\eta_{\text {traction,motor }}$ & {$[1]$} & 0.39 & 0.90 & {$[30,31,33]$} \\
\hline Traction generator efficiency & $\eta_{\text {traction,generator }}$ & {$[1]$} & - & 0.90 & {$[30,33]$} \\
\hline Transmission efficiency & $\eta_{\text {transmission }}$ & [1] & 0.95 & 0.99 & [31] \\
\hline Converter efficiency & $\eta_{\text {converter }}$ & {$[1]$} & - & 0.95 & {$[31]$} \\
\hline Body mean power output & $P_{\text {body,mean }}$ & {$[\mathrm{kW}]$} & 10 & 10 & {$[18,32]$} \\
\hline Body mean efficiency & $\eta_{\text {body,mean }}$ & {$[\mathrm{kW}]$} & 0.7885 & 0.30 & {$[18,32]$} \\
\hline Power auxiliaries & $P_{\text {auxiliaries }}$ & {$[\mathrm{kW}]$} & 2.0 & 2.0 & {$[35]$} \\
\hline Traction motor power max & - & {$[\mathrm{kW}]$} & 235 & 260 & {$[34,36]$} \\
\hline Traction motor idle energy & - & {$\left[l_{\text {diesel }} \cdot h^{-1]}\right.$} & 3.00 & - & [34] \\
\hline Body operation time per container & & {$\left[\mathrm{s} \cdot\right.$ cont $\left.^{-1}\right]$} & 32 & 32 & {$[32]$} \\
\hline
\end{tabular}
book-keeping method using an energy balance with charging and discharging dissipation and selfdischarge effect.

Table 1: Parameters for the driving resistance, drivetrain and body model. 
The models are parametrized with the data sheet of the lithium iron phosphate cell by Thunder Sky LYP and information provided by a WCV manufacturer [37]. A detailed description of the battery model can be found in [38]. The influence of battery temperature on battery performance is not considered, as battery $\mathrm{C}$ rates in WCV are low due to high battery capacities and therefore temperature does not play a major role. The nominal battery capacity is set to $200 \mathrm{kWh}$, while the useable capacity is set to $66 \%$ of the nominal capacity, using defined charge and discharge boundaries [34]. The power dependency of the battery charge and discharge efficiency is reflected by the coefficients $a$ and $b$. These are obtained from a simple equivalent circuit model approach using a powerdependent resistance and are parametrized with the charge and discharge terminal voltage curves for different C-Rates using the approach by Tremblay et al. [39]. The battery model is defined by the following equations:

$$
\begin{aligned}
& \text { IF } P_{\text {eWCV,in }}(t)<0 \text { and FOR } 0.34 \leq \operatorname{SoC}(t) \leq 1.0: \\
& P_{\text {battery,charge }}(t)=a \cdot \operatorname{abs}\left(P_{\text {eWCV,in }}(t)\right)+1 \\
& I F P_{\text {eWCV,in }}(t)>0 \text { and FOR } 0.34 \leq \operatorname{SoC} \leq 1.0: \\
& P_{\text {battery,discharge }}(t)=b \cdot P_{\text {eWCV,in }}(t)+1
\end{aligned}
$$

where $S o C$ is the battery State of Charge, $P_{\text {battery,charge }}$ the battery charge power including charge losses [W], $P_{\text {battery,discharge the battery }}$ discharge power including discharge losses [W], the coefficient $a=-0.0224$ the power dependency of the battery charge efficiency, the coefficient $b=$ -0.0281 the power dependency of the battery discharge efficiency and $t$ the timestep.

\section{Charging infrastructure}

For the definition of the overall energy demand of the eWCV, the charging infrastructure for the battery charging process needs to be considered as well. The implemented model is parametrized for a conductive bi-directional AC charge in Mode-3 with an Electric Vehicle Supply Equipment (EVSE) and an on-board $\mathrm{AC}$ charger. The charger power is set to a total power output of $22 \mathrm{~kW}$. The charging efficiency is fitted to data of a simple wall box from GE and data from a bidirectional AC charger by Kwon et al. [40, 41]. The obtained nominal efficiency of the charger is $91.9 \%$ and is in accordance with the literature $[42,43]$.

Thereby, the overall energy demand of the eWCV and dWCV is defined with a timestep of one second:

$$
\begin{aligned}
& E_{d W C V}=\sum_{t_{\text {start }}}^{t_{\text {end }}} P_{d W C V, \text { in }}(t) \cdot \frac{1}{3600} \\
& E_{\text {eWCV }} \\
& =\sum_{t_{\text {start }}}^{t_{\text {end }}} \frac{P_{\text {battery,discharge }}(t)-P_{\text {battery,charge }}(t)}{\eta_{\text {battery }} \cdot \eta_{\text {battery management }} \cdot \eta_{\text {charger }}} \\
& \cdot \frac{1}{3600}
\end{aligned}
$$

\subsection{Route synthetization}

For the definition of the vehicle mechanical power demand, its speed and acceleration profiles need to be defined. Further information about the number of collected waste container, number of stops and mass of collected waste are important input parameters for the body model.

Real-time data acquisition of the vehicle speed and acceleration profiles via GPS tracking can only be integrated in few cases, as it is associated with a high measurement effort and is often conflicting with data protection guidelines. Instead, the current study uses operational data from three vehicles in one-shift operation for a timeframe of six months, which were provided by a waste management company situated in Berlin, Germany and form the basis for the following synthetic route modeling approach. They cover five different route types, which consist of 387 different day tours collecting one single waste fraction. The operational data consist of customer billing addresses, the number of waste containers per billing address and the mean collected waste mass per vehicle. The operational data covers typical routes of an urban waste collection fleet, which are clustered into following types:

- $\quad$ Tour 1 - High-rise building area

- Tour 2 - Single family house area

- Tour 3 - City center area

- Tour 4-Mixed building area (long distance tour)

- Tour 5 - Mixed building area (short distance tour)

For simplicity and due to data limitations, no distinction is made for the collected mass per container and between different container sizes. Influence of traffic or individual driving styles is also not considered with this modeling method. The operational routine of a day route is divided into transfer drive from / to the recycling hub to / from the collecting area and the collection drive itself. It is comparable to the approach given by Nguyen and Wilson, who divide the waste collection trip into three steps, each with different consumption behaviour: '(1) travelling outside collection areas; (2) idling in front of each household while waste is loaded, while preparing at the garage in the morning or at the end of the day and while queuing to unload waste at transfer stations; and (3) while travelling within an assigned collection area' [13, p. 291]. For the energy demand simulation, the distance of each drive phases is needed to synthesize the route profile. As the given billing addresses are not in real-life route order a route optimization is conducted to identify route phase distances for each individual day tour. Tour start and end point is at the recycling hub where the collected waste fraction is dumped.

Many different Vehicle Routing Problems (VRP) exist, from which the current problem presents a simple Traveling Salesmen Problem (TSP). Vehicle 
visiting points are fixed and constraints such as vehicle capacity or time windows are not taken in account, as it is assumed that operational data considered this already. Optimization is conducted with the objective of shortest paths for the vehicles. In contrast Ewert et al. generate a synthetic demand which draws on more general data, e. g. spatial information and not operational data, and therefore need to define a timeand weight-constrained routing problem [23].

The following equations represent a simplified general mathematical definition of the TSP problem. For simplification multiple constraints, which guarantee the validity of identified routes, are not presented. Given is a set of $n$ route stops enumerated $0,1,2, \ldots, n-1$ which shall be approached with the distance between each pair of route stops $i$ and $j$ defined as $c_{i j}$. The decision variable is further defined as $y_{i j}$ with the following objective function:

$$
\begin{aligned}
& y_{i j} \\
& =\left\{\begin{array}{l}
1, \text { if route stop } j \text { is visited immediatly after stop } i \\
0, \text { otherwise }
\end{array}\right. \\
& \min \sum_{i} \sum_{j} c_{i j} \cdot y_{i j}
\end{aligned}
$$

For solving the TSP, the Open-source Routing Machine (OSRM) ${ }^{4}$ and the Vehicle Routing Opensource Optimization Machine (Vroom) ${ }^{5}$ are used. OSRM is a $\mathrm{C}++$ routing engine based on OpenStreetMap data to compute route distances, Vroom works on top of it and provides the routing optimization. There is a full OSRM integration provided by Vroom. This infrastructure is not limited to TSP and can also solve Capacitated Vehicle Routing Problem (CVRP) and Vehicle Routing Problem with Time Windows (VRPTW). Vroom solvers are based on Christofides heuristic (TSP) and Solomon I1 heuristics (CVRP and VRPTW) [44, 45, 46]. TSP heuristic is based on The Nearest Neighbour Method [47]. For the present study the software package Docker Desktop was used to implement an own local server infrastructure with OSRM and VROOM web API in order to overcome OSRM server restrictions.

After setting the billing addresses into optimal route order the driving distance of each drive phase could be determined (the transfer drive from the recycling hub to the collecting area, the collection drive and the transfer drive from the collecting area to the recycling hub). In the following, speed, acceleration and body profiles are synthesized. Standard travel profiles are used for the transfer drives. The Worldwide harmonized Light vehicles Test Procedure class 1 is used, which was developed for the determination of exhaust gas emissions and fuel / electricity demand [48]. The standard profile covers a distance of $3323.8 \mathrm{~m}$ and involves values for vehicle speed and acceleration with a resolution of one second. In case of a longer identified transfer drive of the WCV of a day

${ }^{4}$ http://project-osrm.org/ tour than the standard profile, a multiplicate of the profile is used. In case of a shorter transfer drive only a subsection is used.

For the collection drives first of all the number of WCV stops per day tour is identified. The minimum distance for an individual start/stop of the WCV between two billing addresses is set to $30 \mathrm{~m}$. If two addresses are closer to each other than this distance, they are served together as one WCV stop. This is also within the range of the mean distance between two stops as determined by Knoke [19]. The waiting time of the vehicle for the collection and transport of waste container to the vehicle body is fixed and set to $40 \mathrm{~s}$. A speed trapezoidal model is assumed between to WCV stops, which is a common and proved approach [49]. Constant acceleration / deceleration of $0.60 \mathrm{~m} \mathrm{~s}^{-2}$ and a maximum speed of $30 \mathrm{~km} \mathrm{~h}^{-1}$ are used [18]. For simplification and the reduction of computing time, the stops in the final synthesis of the speed and acceleration profiles are divided evenly over the entire collection phase. The body profile defines the time of body deployment during a WCV stop, which is dependent on the number of waste container per stop and based on the assumption of a static energy demand of $90 \mathrm{Wh}$ per duty cycle and waste container and a static body output power.

\subsection{Total cost of ownership}

The TCO analysis follows a standard methodology to summarize all occurring costs of a vehicle during its lifetime. This study uses the approach described in [50] adding the framework of Well-to-Wheel greenhouse gas (GHG) emissions costs. As the costs are related to different moments in time they need to be transferred to their present value.

To calculate the present value of one-time costs and recurring costs occurring in the future following equations are used:

$$
\begin{aligned}
& P V_{\text {one-time }}(C(t))=C(t) \cdot \frac{1}{(1+r)^{T}} \\
& P V_{\text {recurring }}(C(0))=C(0) \cdot \frac{(1+r)^{T}-1}{r \cdot(1+r)^{T}}
\end{aligned}
$$

where $P V_{\text {one-time }}$ is the present value of future onetime costs $[€]$ with $C(t)$ being the one-time costs at the time $t, P V_{\text {recurring }}$ is the present value of future recurring costs $[€]$ with $C(0)$ being the amount of annual recurring costs $[€], r$ is the real discount rate and $T$ the time in years.

The current study considers investment costs, maintenance and operation costs and residual costs. A nominal interest rate of $5 \%$ and inflation rate of $2 \%$ is assumed, which leads to a real discount rate of $2.9 \%$. This is a conservative assumption, as current economic parameters show more lucrative conditions. Nevertheless, it shall represent long-term and risk-

${ }^{5}$ http://vroom-project.org/ 
included financing interest rates of companies and is in agreement with current studies [51]. WCV investment costs are set within the boundaries of cited literature [26, 27, 28, 29]. Table 2 gives an overview of all considered cost assumptions. In comparison, Ewert et al. assume an interest rate of $4 \%$ and a vehicle lifetime of 10 years, but did not consider that eWCV maintenance are likely to be lower than for dWCV [23].

The annual mileage and distance-specific energy demand of eWCV and $\mathrm{dWCV}$ is based on the mean value of the energy demand simulation of all daily routes and projected to an annual operation. The final TCO is calculated according to following equations:

$$
\begin{gathered}
P V_{\text {investment }}=C C_{W C V}-C C_{\text {subsidy. } W C V}+C C_{\text {charging }} \\
P V_{\text {omc }}=P V_{\text {recurring }}\left(o m c_{F u e l} \cdot E_{W C V}\right)+o m c_{W C V} \\
\cdot M_{W C V}+o m c_{\text {charging }}+o m c_{\text {Tax }} \\
+o m c_{\text {Insur }}
\end{gathered}
$$

where $C C_{W C V}$ is investment costs for the WCV [€], $C C_{\text {subsidy. } W C V}$ the state subsidy for the vehicle purchase $[€], C C_{\text {charging }}$ the investment costs for the $22 \mathrm{~kW}$ AC charging infrastructure $[€], o m c_{F u e l}$ the energy costs $\left[€ \cdot \mathrm{kWh}^{-1}\right], E_{W C V}$ the annual WCV energy demand $[\mathrm{kWh}], \quad o m c_{W C V}$ the specific WCV maintenance cost $\left[\left[€ \cdot \mathrm{km}^{-1}\right], M_{W C V}\right.$ the WCV annual mileage $[\mathrm{km}]$ and $o m c_{\text {charging }}+o m c_{\text {Tax }}+o m c_{\text {Insur }}$ the annual costs for charging maintenance, taxes and insurance $\left[€ \cdot \mathrm{a}^{-1}\right]$.

Two methods are implemented for the TCO evaluation of eWCV and dWCV. First, the simple difference in the TCO between eWCV and dWCV is calculated, according to the following equation:

$$
\triangle T C O=T C O_{e W C V}-T C O_{d W C V}
$$

Second, the virtual costs of the saved Well-to-Wheel greenhouse gas (GHG) emissions are calculated according to the following equations:

$$
\begin{aligned}
& E M_{W C V}=e m_{f u e l} \cdot E_{W C V} \cdot T \\
& \operatorname{Costs}_{C O_{2, e q} \text { saved }}=\frac{T C O_{e W C V}-T C O_{d W C V}}{\left(E M_{d W C V}-E M_{e W C V}\right)}
\end{aligned}
$$

where $E M_{W C V}$ are the overall Well-to-Wheel GHG emissions resulting from WCV fuel demand during the considered timeframe, em $_{\text {fuel }}$ are the specific Well-toWheel GHG emissions of the WCV fuel [g $\mathrm{CO}_{2, \mathrm{eq}} \cdot \mathrm{kWh}^{-1}$ ], $T$ the time in years and Costs $\mathrm{CO}_{2, \text { eq }}$ saved are the virtual costs of the saved GHG emissions through the implementation of an eWCV.

As eWCV investment costs and the considered specific Well-to-Wheel GHG emissions of the electricity used have a high impact on the TCO analysis two further scenarios are defined according to Table 3. Specific GHG emission for diesel are calculated to be $566 \mathrm{~g} \mathrm{CO}_{2, \mathrm{eq}} \cdot \mathrm{kWh}^{-1}$ based on $[55,56$, 57]. For the year 2018, GHG emissions for electricity in Germany are estimated at $473 \mathrm{~g} \mathrm{CO}_{2, \mathrm{eq}} \cdot \mathrm{kWh}^{-1}$ [23]. Both emission factors are considered for the scenario

\begin{tabular}{|c|c|c|c|c|}
\hline Parameter & & Unit & dWCV & $\mathrm{eWCV}$ \\
\hline Investment costs WCV & $C C_{W C V}$ & {$[€]$} & 550,000 & 210,000 \\
\hline Investment costs charging & $C C_{\text {charging }}$ & {$[€]$} & - & 1,000 \\
\hline State subsidy WCV & $C C_{\text {subsidy. } W C V}$ & {$[€]$} & - & 40,000 \\
\hline Annual depreciation WCV & $\operatorname{dep}_{W C V}$ & {$\left[\% \cdot \mathrm{a}^{-1}\right]$} & 82.7 & 78.6 \\
\hline Fuel (diesel/electricity) costs & omc $c_{\text {Fuel }}$ & {$\left[€ \cdot \mathrm{kWh}^{-1}\right]$} & 0.179 & 0.105 \\
\hline Spec. energy demand WCV & $E_{W C V}$ & {$\left[\mathrm{kWh} \cdot \mathrm{km}^{-1}\right]$} & 5.0512 & 1.7322 \\
\hline Maintenance costs WCV & $o m c_{W C V}$ & {$\left[€ \cdot \mathrm{km}^{-1}\right]$} & 0.50 & 0.325 \\
\hline Mileage WCV & $M_{W C V}$ & {$\left[\mathrm{~km} \cdot \mathrm{a}^{-1}\right]$} & 13,010 & 13,010 \\
\hline Maintenance costs charging & omc charging & {$\left[€ \cdot \mathrm{a}^{-1}\right]$} & - & 350 \\
\hline Tax costs & omc $_{\text {Tax }}$ & {$\left[€ \cdot \mathrm{a}^{-1}\right]$} & 556 & - \\
\hline Insurance costs & $o m c_{\text {Insur }}$ & {$\left[€ \cdot \mathrm{a}^{-1}\right]$} & 2,000 & 2,000 \\
\hline Real discount rate & $r$ & [1] & 0.029 & 0.029 \\
\hline Lifetime / TCO observation period & $T$ & [a] & 10 & 10 \\
\hline
\end{tabular}
Base using the economic assumption highlighted in Table 2. Scenario 1 assumes eWCV charging with renewable energy electricity, which results in specific GHG emissions of $25 \mathrm{~g} \mathrm{CO}_{2, \mathrm{eq}} \cdot \mathrm{kWh}^{-1}$ [23]. Scenario 2 considers reduced eWCV investment costs of $420,000 €$, which corresponds to the factor 2 of the dWCV investment costs.

Table 2: Parameters for the TCO calculation for the eWCV and dWCV of the base scenario as given in [34], [52], [53], [54]. 
Table 3: Parameters for the TCO analysis of the scenario 1 and 2.

\begin{tabular}{|c|c|c|c|c|c|}
\hline Parameter & & Unit & $\begin{array}{c}\text { Scenario } \\
\text { Base }\end{array}$ & Scenario 1 & Scenario 2 \\
\hline Investment costs eWCV & $C C_{e W C V}$ & {$[€]$} & 550,000 & 550,000 & 420,000 \\
\hline Investment costs dWCV & $C C_{d W C V}$ & {$[€]$} & 210,000 & 210,000 & 210,000 \\
\hline Specific GHG emissions electricity & em electricty & {$\left[\mathrm{kg} \mathrm{CO}_{2, \mathrm{eq}} \cdot \mathrm{kWh}^{-1}\right]$} & 0.473 & 0.025 & 0.473 \\
\hline Specific GHG emissions diesel & em diesel & {$\left[\mathrm{kg} \mathrm{CO}_{2, \mathrm{eq}} \cdot \mathrm{kWh}^{-1}\right]$} & 0.556 & 0.556 & 0.556 \\
\hline
\end{tabular}

\section{Results and discussion}

The results and discussion section presents the obtained results of the route synthetization, the energy demand simulation and the TCO of the analysed 387 different waste collection day tours. Each simulation run comprises of one day tour for a full 8 hours shift with a temporal resolution of one second.

\section{Route Synthetization}

Based on the route optimization of the billing addresses the optimal address order could be identified and the individual route driving distances for the transfer and collection drive phase can be determined for the synthetization of the speed, acceleration and body profiles. Figure 1 show maps of sample day tours of the identified routes of all five examined route types. Maps are generated using the tool OSMnx for the representation of street networks [58]. Blue lines represent the route phase of transfer drive, while red lines the collection drive, respectively. The red circle shows the location of the recycling hub.
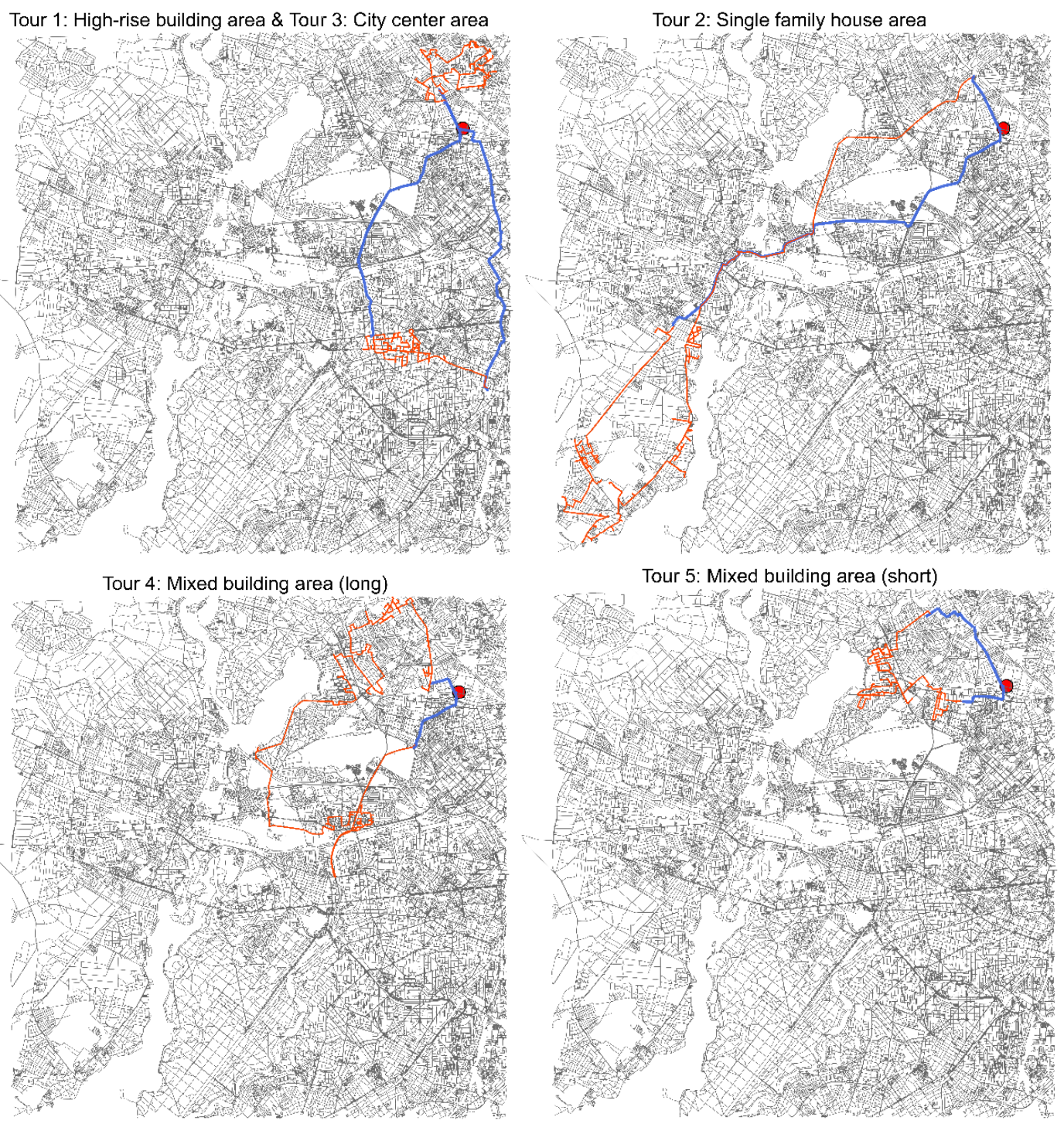

Figure 1: Sample day tours of the identified routes of all examined tour types, in the upper left map Tour 1 is located at the top of the map, while Tour 3 in the middle. 

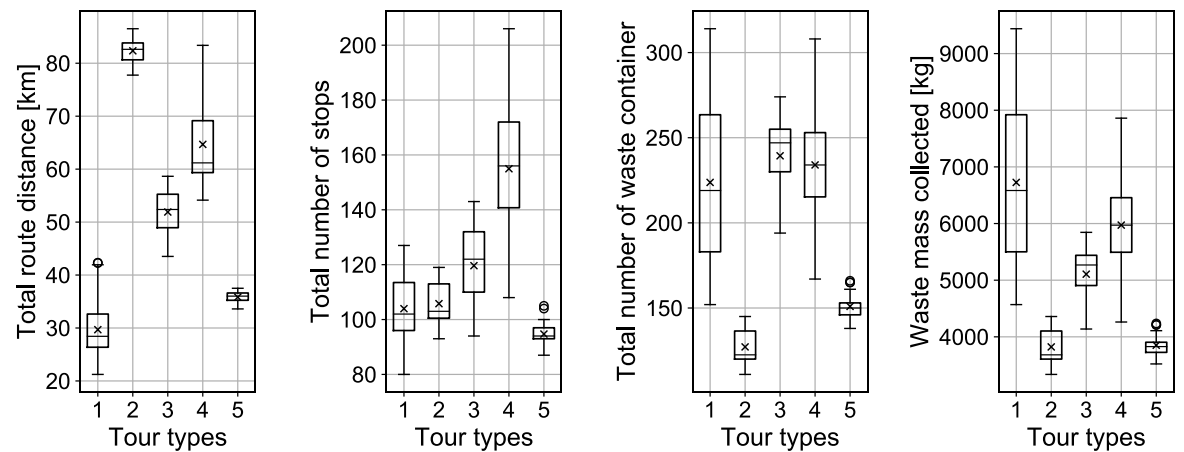

Figure 2: Total route distance, number of stops, number of waste containers and waste mass for each tour type (Boxplot: $x$ is representing arithmetic mean and black line median value).

An overview of the characteristics and main parameters identified for the five route types is shown in Figure 2. The total distance (sum of transfer and collection drive), the number of stops and waste containers and the assumed collected waste mass per day route are presented. The average ratio of the transfer and collection drive distance is 6\%/94\% (Tour 1), $24 \%$ / $76 \%$ (Tour 2), $42 \%$ / $58 \%$ (Tour 3), $9 \% / 91 \%$ (Tour 4 ), $15 \% / 85 \%$ (Tour 5). Across all tour types the average is $20 \% / 80 \%$. It is obvious that the presented tour types differ in their characteristics. Tour 1 is characterized by very short transfer drive and a high number of waste containers and waste mass collected, while Tour 2 shows a long transfer drive and a low number of collected waste containers and overall waste mass.

\section{Energy Demand Simulation}

Figure 3 shows the distribution of the specific and total energy demand of the eWCV and dWCV without any distinction between the examined route types. For the eWCV, the energy losses through the charging infrastructure are included and thus represents the electricity demand from the grid, while for the dWCV the energy content of the diesel demand is presented. The mean absolute and specific values of the two vehicle types are $87 \mathrm{kWh} / 1.85 \mathrm{kWh} \cdot \mathrm{km}^{-}$ $1 / 16.22 \mathrm{kWh} \cdot \mathrm{t}^{-1}$ for the eWCV and $255 \mathrm{kWh} / 5.43 \mathrm{kWh} \cdot \mathrm{km}^{-1} / 47.14 \mathrm{kWh} \cdot \mathrm{t}^{-1}$ for the $\mathrm{dWCV}$. Based on these results the total energy demand of the simulated eWCV lies around $66 \%$ below that of the dWCV. This difference is due to the higher efficiency of the electrified drivetrain and vehicle body and recuperation potential. The variation of the energy demand within each vehicle type represented through the boxplots reflects the high impact of route type specification on the energy demand.

The average diesel demand stated by the waste disposal company for the considered day routes in this study is around $521 \cdot 100 \mathrm{~km}^{-1} / 5.04 \mathrm{kWh} \cdot \mathrm{km}^{-1}$ for the dWCV fleet, which is only $7 \%$ below the mean simulation result of $561 \cdot 100 \mathrm{~km}^{-1} / 5.43 \mathrm{kWh} \cdot \mathrm{km}^{-1}$. A more detailed validation process with a day route specific diesel consumption is not possible due to data limitations. Reference studies for the energy demand of eWCV and dWCV also show comparable values to the presented results. Larsen et al. measured a massspecific diesel consumption between 1.4 and 10.11 diesel $\cdot t_{\text {waste }}{ }^{-1}$, which differs according to analyzed collection schemes. A WCV manufacturer states a mean energy demand of $50-601.100 \mathrm{~km}^{-1} / 5.15$ $6.19 \mathrm{kWh} \cdot \mathrm{km}^{-1}$ for a dWCV and $2.03-2.64 \mathrm{kWh} \cdot \mathrm{km}^{-1}$ for eWCV [34]. Nagel et al., who also cite a WCV manufacturer, state a mean value of eWCV of $1 \mathrm{kWh} \cdot \mathrm{km}^{-1}$ [26], Erdinç et al. give $0.86 \mathrm{kWh} \cdot \mathrm{km}^{-1}$ [25], while Gräbener found a value of $2.23 \mathrm{kWh} \cdot \mathrm{km}^{-1}$ [22]. While it is obvious that cited literature values are within the range of the presented energy demand simulation results, eWCV studies lack a more detailed description of the energy demand distribution. It also becomes clear that mean values for the energy demand of WCV has limited significance for a feasibility analysis, as vehicle performance shows large fluctuation within and between different route types.
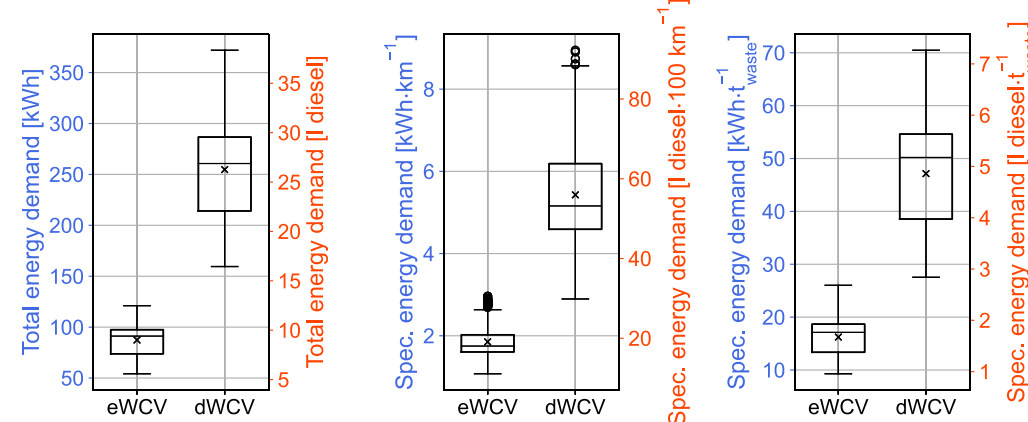

Figure 3: Specific and total energy demand of the examined WCV types. 

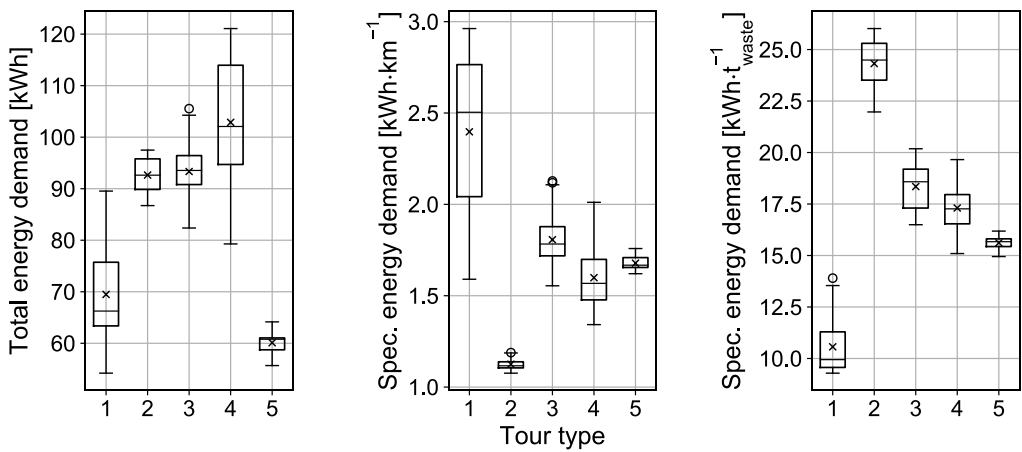

Figure 4: Absolute, distance-specific and waste mass-specific total energy demand of eWCV.

Figure 4 shows the total energy demand and the distance-specific and waste mass-specific energy demand of the eWCV on all routes examined. In combination with the underlying route parameters, the influence of the total route distance and the number of collected mass containers on the total and specific energy demand can be analyzed. Route 4 shows a high total energy demand and is characterized by a high tour distance and number of containers, while route 5 shows a low total energy demand with short tour distance and small number of containers. In regard to the specific energy demands, route 2 shows the overall minimal distance-specific value with $1.08 \mathrm{kWh} \cdot \mathrm{km}^{-1}$ and the maximum mass-specific energy with $26.02 \mathrm{kWh} \cdot \mathrm{kg}^{-1}$, while route 1 includes the overall maximum distance-specific value with $2.96 \mathrm{kWh} \cdot \mathrm{km}^{-}$ ${ }^{1}$ and the minimal mass-specific with $9.29 \mathrm{kWh} \cdot \mathrm{kg}^{-1}$. Route 2 shows high travel distances and a low number of waste containers, while route 1 comprises short travel distances and a high number of waste containers and collected waste mass. This reveals that the total and specific energy demand of a WCV is highly influenced by these two route factors, and can therefore vary widely between different day tours. Larsen et al. also highlighted a variation in energy demand connected to the respective area, the route distance and the amount of waste collected [12].

Figure 5 presents the distribution of the total energy requirement across the different route phases (transfer and collection drive) as well as the operation mode (body aggregates and propulsion) of all examined route types for the eWCV. These performance factors also correlate strongly with the structure of the route data. The mean share of energy used for the transfer drive is $12 \%$ and $88 \%$ for the collection drive. In case of dominating transfer drive route types (route 2 and 3 ), the share of energy used for transfer drive increases, although never exceeding $26 \%$. The mean share of energy used for body aggregates is $39 \%$ and $61 \%$ for propulsion. It rises to $56 \%$ (route 1 ) in case of a high number of waste container and mass collected in combination with a short travel distance. [30] gives a ratio for the work aggregate of $32 \%$ of the total energy demand, which is in correlation with the presented results. Consequently, the energy demand is dominated by the collection drive. eWCV show promising advantages to minimize energy demand, as they have the potential to recuperate braking energy and show improved motor efficiency during the collection phase with a high number of start/stop movements. Further energy savings could be implemented with improved body configurations, which is currently considered by some eWCV manufacturers [34].

Figure 6 displays the total energy demand of all vehicle day tours and its variation compared to the base case, dependent on three sensitivity parameters. Analyzed parameters are the drivetrain efficiency (equation (6)), battery efficiency (values only decreased and no power dependency considered, compare equation (12) and (13)) and duty cycle energy demand. The change in total energy demand shows a linear correlation on the analyzed parameter range, while the resulting distribution of the day tours is not affected by the parameter variation. The duty cycle energy demand shows a minor influence, with a maximum change in the total energy demand of $8.7 \%$.The drivetrain efficiency shows a maximum change in the total energy demand of $6.4 \%$ and the battery of $11.6 \%$. The battery efficiency has the highest impact, as the battery powers the vehicle traction and body.

The energy demand simulation shows a maximum battery capacity usage of the eWCV including recuperated energy of all examined day tours of $111 \mathrm{kWh}$, while the mean value lies at $80 \mathrm{kWh}$. Recuperation energy has a mean share of $25 \%$. Nagel et al. show a maximum energy demand of $142 \mathrm{kWh}$ [24]. The considered $200 \mathrm{kWh}$ battery with the assumed charge/discharge boundaries leaves a theoretical rest capacity of $104 \mathrm{kWh}$ at the End of Life with a State of Health of $80 \% .7 \%$ of all considered routes, i.e. all routes of route type 4 , could therefore not be operated according to the above assumptions. Battery capacity usage therefore needs to be analyzed in dependency on the operated eWCV routes to guarantee an interruption-free operation. eWCV with 

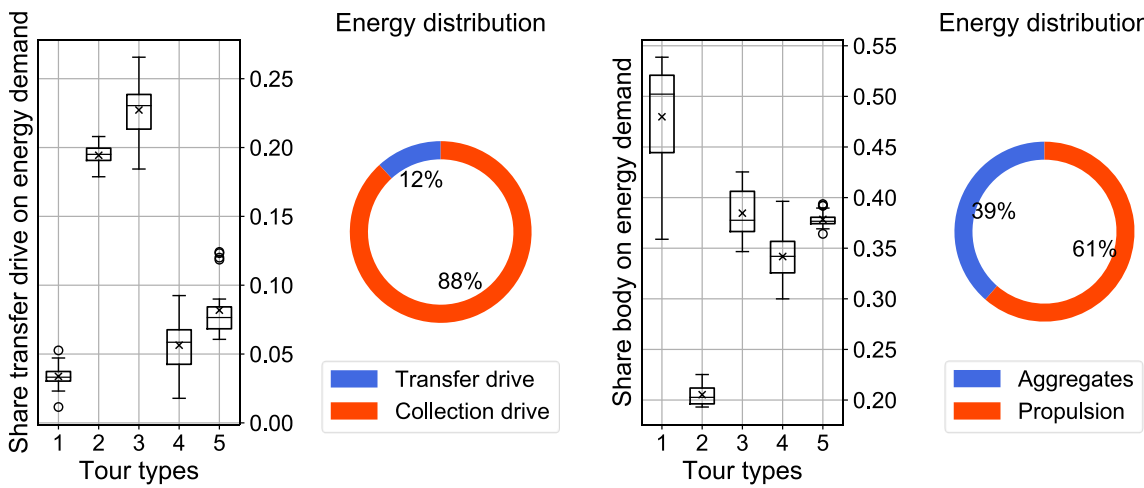

Figure 5: Division of total energy demand according to route phase (left) and operation mode (right) of eWCV.

a higher battery capacity are available, and the cited WCV manufacturer plans to increase battery capacity to $264 \mathrm{kWh}$ with their $2^{\text {nd }}$ battery version [34].

Charging times for the eWCV battery with the considered $22 \mathrm{~kW}$ charger $(20.1 \mathrm{~kW}$ charging power after losses of charger, BMS and battery) fluctuate between 2.5 and $5.5 \mathrm{~h}$ due to the different energy demands of the examined routes. Vehicle loading times play an important role in the management of potential future eWCV fleets. The routes considered in the present study are processed in one-shift operation. This means that the vehicles are only in use for approximately eight hours a day, which leaves enough time to charge the battery overnight. In the case of a two-shift operation, the vehicle batteries must either be dimensioned large enough to accomplish both shifts, or an intermediate fast-charge mode would be necessary. Further studies should be conducted regarding the ageing of the vehicle battery and its performance in respect to its usage cycles and charging concepts, which is not the objective of this study.
The presented results of the energy demand calculation are in the range of literature values, and dWCV results could be validated with real-life mean diesel consumption of dWCV. Nevertheless, further validation with real-life data such as diesel consumption of specific day routes or route profile data (e.g. velocity, acceleration, engine speed) could increase overall accuracy of the presented method, this is the case in the approach taken by Bender et al. [17] and will be the objective of future research.

In comparison to generic energy demand simulation approaches using a tour synthetization with demographic properties and the spatial street layout (compare Ewert et al. [23]), the presented method relies on vehicle and route specific operational data. Possible optimization uncertainties for the generation of optimal operational points are therefore reduced. GPS based route synthetization (compare Erdinç et al. [25]) can achieve even higher accuracy but are limited by the number of analysed routes due to high measurement effort.
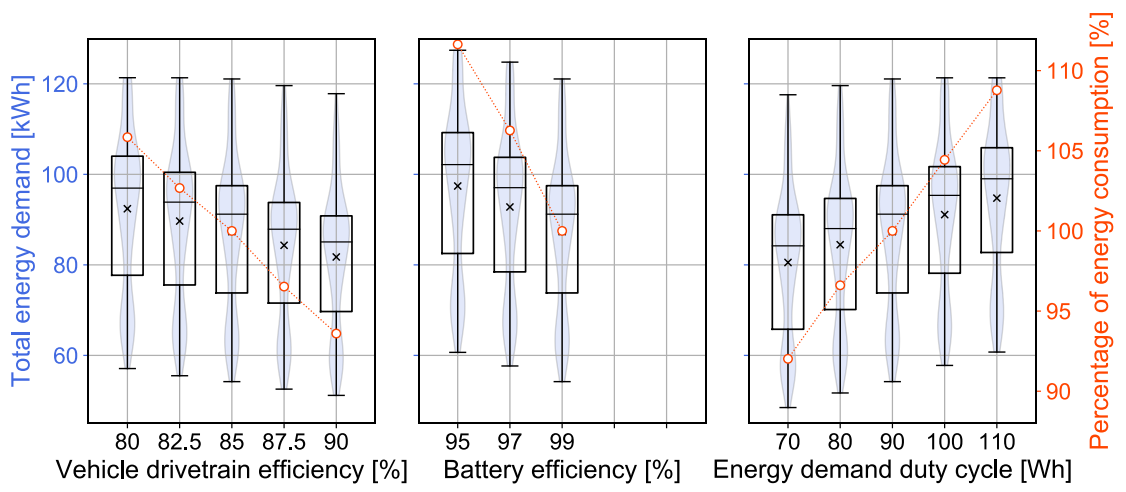

Figure 6: Sensitivity analysis with variation of drivetrain efficiency, battery efficiency and duty cycle energy demand. Total energy demand is presented in boxplots combined with blue violin plots showing the distribution of all day tours, total energy demand variation in percentage is shown with red circles.

\section{Total cost of ownership}

Absolute values for the TCO calculation of the scenario Base are 567,239€ for eWCV with annual $\mathrm{CO}_{2 \text {,eq }}$ Well-to-Wheel emissions of $11.4 \mathrm{t} \mathrm{CO}_{2 \text {,eq }} \cdot \mathrm{a}^{-1}$, while TCO calculations for dWCV show 325,854€ with $39.3 \mathrm{tCO}_{2, \mathrm{eq}} \cdot \mathrm{a}^{-1}$. Literature values using a comparable approach to analyze TCO of WCV could not be located. Therefore, the values cannot be set in comparison to other calculations. Figure 7 presents the difference in the TCO between eWCV and dWCV as a function of electricity price, diesel price and annual mileage, without considering possible Well-to-Wheel $\mathrm{CO}_{2, \text { eq }}$ emission costs. While the TCO values for eWCV are above those for $\mathrm{dWCV}$, the spread between 

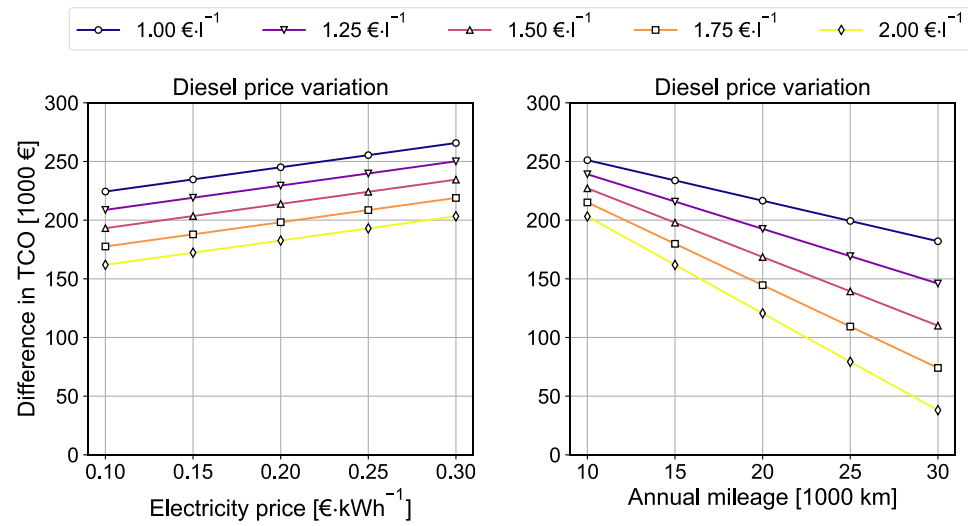

Figure 7: Difference in TCO between eWCV and $d W C V$ as a function of diesel price, electricity price and annual mileage without the consideration of possible emission costs.

both shows high sensitivity regarding diesel price and annual mileage. The lowest difference is achieved with a high annual mileage and diesel price. However, even with a mileage of $30,000 \mathrm{~km}$ (approximately corresponding to two-shift operation) and a diesel price of $2.00 € \cdot 1^{-1}$, a TCO difference of $38,064 €$ remains.

Due to the high sensitivity of diesel price and mileage, these two factors are examined further. Figure 8 shows the virtual costs of saved Well-to-Wheel $\mathrm{CO}_{2 \text {,eq }}$ emissions through the electrification of a dWCV for all three scenarios (compare Table 2 and Table 3 ) as a function of these two sensitivity factors. In its Climate Protection Program 2030 (Klimaschutzprogramm 2030), the German government defines a fixed $\mathrm{CO}_{2 \text {,eq }}$ emission price of $25 € \cdot \mathrm{t}^{-1}$ in 2021 , which shall rise to $55 € \cdot \mathrm{t}^{-1}$ in 2025 and is indicated in the figure with the dashed black line [59]. The base scenario reveals that with current economic constraints no economic use case can be identified. Even in the case of diesel prices rising to approximately $2.00 € \cdot 1^{-1}$ and an annual mileage of $30,000 \mathrm{~km}$, identified costs for saved $\mathrm{CO}_{2 \text {,eq }}$ emissions of $58 € \cdot \mathrm{t}^{-1}$ are still above the 2025 price. Using the parameter given in Scenario 1, eWCV can, at least in the mid-term, become an economical advantageous solution with costs for saved $\mathrm{CO}_{2 \text {,eq }}$ emissions amounting to $42 € \cdot \mathrm{t}^{-1}$. The greatest potential for economic feasibility is given in Scenario 2, under which the $2021 \mathrm{CO}_{2}$ emission price of $25 € \cdot \mathrm{t}^{-1}$ is achieved even with a diesel price of about $1.30 € \cdot 1^{-1}$ and an annual mileage of $30,000 \mathrm{~km}$. $\mathrm{A} \mathrm{CO}_{2}$ emission price mechanism shows high potential for economic regulation to create economical advantageous pathways towards an electrification of WCV. With current economic constraints, the electrification of WCV is accompanied by slightly higher costs. Cost benefits become achievable with the implementation of an effective emission cost mechanism, an increasing share of renewable electricity, and reduced eWCV investment costs, for example via potential future mass market production or state subsidies.

The presented innovative TCO approach shows compared to the standard TCO methodology (compare Ewert et al. [23]) additional costs associated with the analysed fuel switch and directly integrates emission price mechanisms. Therefore, necessary measures per vehicle can be better identified and used by decision makers. The presented energy demand simulation and TCO method is therefore a simple and accurate possibility for WCV fleet operators to analyse their fleet and possible fuel switch scenarios.

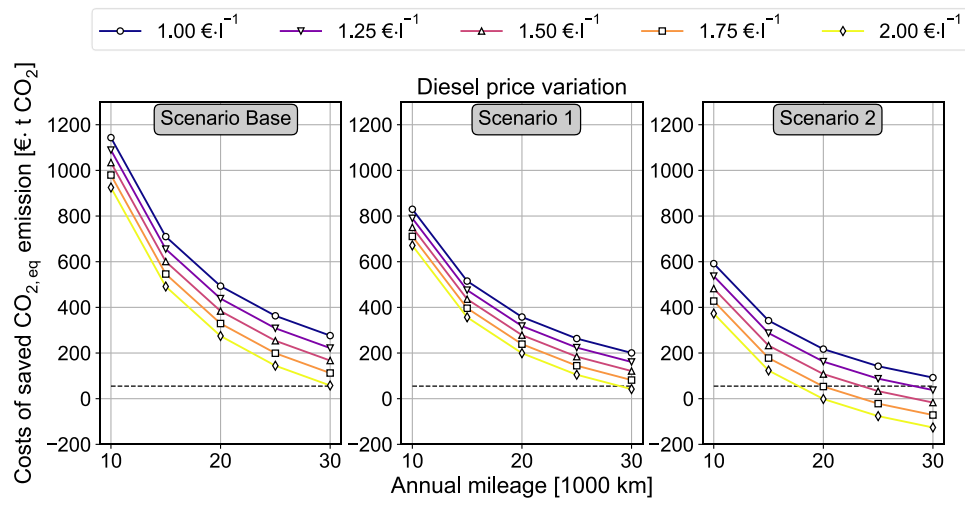

Figure 8: Difference in TCO between eWCV and dWCV as a function of mileage for all three considered scenarios, black dashed line indicates $\mathrm{CO}_{2, e q}$ emission price of $55 € \cdot t^{-1}$. 


\section{Conclusion}

Electrification of WCV can be a promising solution for the decarbonization of the municipal waste transport sector. Through a simulation-based approach of 387 real-life WCV operation tours, this study shows that relevant energy savings can be achieved with the implementation of eWCV. The total and specific energy demand varies between and within route types and is highly influenced by route distance and number of containers and thus by overall waste mass collected. Further, it is dominated by the collection drive, where eWCV have promising advantages through the possibility of recuperation and improved motor efficiency. For this reason, mean energy demand values have only limited validity. Vehicle battery capacity needs to be carefully dimensioned according to operating routes and fleet management. In general, however, currently available eWCV configurations can fully serve the examined one-shift route profiles.

For eWCV range expansion further energy savings are necessary, which could be achieved through improved body configurations or by adapting container collection as the relaunch of collection points. In Particular, two-shift operation needs to be further analysed for an optimal fleet hub management, which includes charging infrastructure and time scheduling. As two-shift operation is not always considered by waste management companies, the transition to this system might increase the economic feasibility of eWCV in case of an extensive vehicle usage. Noise emissions of eWCV are considerably lower than for dWCV; this offers more options to spread the collection periods over the day, which is in favour of a two-shift operation [60]. Influence of different waste fractions on energy demand were not analysed. As studies show, these have a high relevance for the energy demand analysis [12].

The economic analysis shows that the TCO of eWCV are higher than for dWCV under current economic constraints, but that economical advantageous pathways for an electrification of WCV are possible. High sensitivity regarding fuel price and vehicle annual mileage could be identified. Combined with an effective emission price mechanism, reduced eWCV investment costs or $\mathrm{CO}_{2, \text { eq }}$ electricity emissions can bring the TCO of eWCV below that of dWCV. Manufacturers of eWCV and batteries could likely cut down investment prices through mass market entry, while political instruments such as subsidies and other price mechanisms should be implemented even further to open economic electrification pathways in the shortterm. This also includes the structure of the electricity price in Germany concerning taxes and fees, especially for renewable energies. Regardless of the development of price mechanisms, costs savings can be achieved using the available possibilities to participate in the electricity balancing market as well as opportunities given by the waste treatment processes. Further research in this topic has been conducted and will be published in the near future.

The proposed methodology is a practical approach for forecasting energy demand and costs of eWCV and can give decision makers valuable information concerning moving from diesel- to electric-driven WCV. Nevertheless, the energy demand simulation uses several assumptions for technical parameters, which can vary dependent on WCV and battery products and further technology development. The sensitivity analysis shows the influence of some parameter but cannot provide an extensive analysis. But the open-source approach of this methodology shall give the scientific community the chance to incorporate future results and technical knowledge in order to reduce uncertainty in the assumptions made. The simulation results can only be validated with a mean real-life diesel consumption. This could be improved by validating the simulation and optimize parameter assumptions with real-life measurements for $\mathrm{dWCV}$ and $\mathrm{eWCV}$, which is the objective of future research. It is intended, that a future project shall build on the results of the study 'Grid-beneficial Integration of Hybrid Waste Collection Vehicles' and involves real-life testing of eWCV and vehicle-to-grid and gridto-vehicle application. Beside this the developed simulation tool shall be extended with fuel cell driven $\mathrm{WCV}$ in order to compare current decarbonization pathways for WCV.

At this point, this study can deliver a valuable contribution to the simulation and determination of WCV energy demand in daily operation based on an open-source energy demand simulation including a route synthetization approach. It can be used as basis for further scientific or industry studies on the electrification of WCV fleets.

\section{Acknowledgments}

The study 'Netzdienliche Integration hybrider Entsorgungsfahrzeuge' (Grid-beneficial Integration of Hybrid Waste Collection Vehicles) was funded by the Berlin Senate and the European Regional Development . The current paper builds on the experiences made in this study, of which the authors were part of. The authors thank all partners and the funding agencies. 


\section{$6 \quad$ Literature}

[1] Fachausschuss Nachhaltiges Energiesystem 2050 des Forschungsverbunds erneuerbarer Energien, Eine Vision für ein nachhaltiges Energiekonzept auf Basis von Energieeffizienz und 100\% erneuerbaren Energien, Berlin, 2010.

[2] Kraftfahrt-Bundesamt, Fahrzeugzulassungen, 2018.

[3] Naturstrom AG, "energizukunft," 2018. [Online]. Available: https://www.energiezukunft.eu/mobilitaet/vorreiter-fuer-emobilitaet/.

[4] DGAW e.V., "DGAW e.V.," 2709 2019. [Online] Available: https://www.dgaw.de/wpcontent/uploads/DGAW-Pressemitteilung-AlternativeAntriebe-final.pdf. [Accessed 3001 2020].

[5] Webredaktion (Magistratsabteilung 48), "Erstes ElektroMüllsammelfahrzeug Österreichs in Betrieb," [Online]. Available: https://www.wien.gv.at/umwelt/ma48/fuhrpark/elektromuellsammelfahrzeug.html.

[6] C. Rosengren, "Volvo unveils another electric refuse collection vehicle," 2019

[7] B. G. Wilson and B. W. Baetz, "Modeling Municipal Solid Waste Collection Systems Using Derived Probability Distributions. I: Model Development," Journal of Environmental Engineering, vol. 127, no. 11, pp. 1031-1038, November 2001.

[8] J. W. Everett and P. Riley, "Curbside Collection of Recyclable Material: Simulation of Collection Activities and Estimation of Vehicle and Labour Needs," Journal of the Air \& Waste Management Association, vol. 47, no. 10, pp. 10611069, 1997.

[9] J. W. Everett, S. Maratha, R. Dorairaj and P. Riley, "Curbside collection of recyclables I: Route time estimation model.," Resources Conservation and Recycling, vol. 22, no. 3, p. 177192, 1998.

[10] J. W. Everett, R. Dorairaj, S. Maratha and P. Riley, "Curbside collection of recyclables II: Simulation and economic analysis.," Resources Conservation and Recycling, vol. 22 , no. 3-4, pp. 217-240, 1998.

[11] U. Sonesson, "Modelling of waste collection - a general approach to calculate fuel consumption and time," Waste Management \& Research, vol. 18, pp. 115-123, 2000.

[12] A. W. Larsen, M. Vrgoc and T. H. Christensen, "Diesel consumption in waste collection and transport and its environmental significance," Waste Management \& Research, vol. 27, pp. 652-659, 2009.

[13] T. Nguyen and B. Wilson, "Fuel consumption estimation for kerbside municipal solid waste (MSW) collection activities," Waste Management \& Research, vol. 28, pp. 289-297, 2010.

[14] B. Wu, C.-C. Lin, Z. Filipi, H. Peng and D. Assanis, "Optimal Power Management for a Hydraulic Hybrid Delivery Truck," Vehicle System Dynamics, vol. 42, no. 1-2, pp. 23-40, 2004.

[15] F. A. Bender, M. Kaszynski and O. Sawodny, "LocationBased Energy Management Optimization for Hybrid Hydraulic Vehicles," in American Control Conference (ACC), Washington DC, 2013

[16] F. A. Bender, M. Kaszynski and O. Sawodny, "Drive Cycle Prediction and Energy Management Optimization for Hybrid
Hydraulic Vehicles," IEEE Transactions on Vehicular Technology, vol. 62, no. 8, pp. 3581-3592, October 2013.

[17] F. A. Bender, T. Bosse and O. Sawodny, "An investigation on the fuel savings potential of hybrid hydraulic refuse collection vehicles," Waste Management, vol. 34, pp. 1577 1583,2014

[18] G. Sandkühler and Faun Umwelttechnik GmbH \& Co. KG, "Abfallsammelfahrzeug mit Dieselelektrischem Hybridantrieb," Sonderausgabe ATZ, pp. 44-55, 2010.

[19] T. Knoke, "Entwurf und Betrieb hybrid-elektrischer Fahrzeugantriebe am Beispiel von Abfallsammelfahrzeugen," Shaker, Aachen, 2010.

[20] S. Schneider, "Effizienz- und Wirtschaftlichkeitsanalyse des elektrischen $18 \mathrm{t}$ Lastwagens E-FORCE von Feldschlösschen Getränke AG," 2014

[21] S. Gräbener, Methodische Entwicklung und Bewertung von Elektrifizierungskonzepten für innerstädtische Nutzfahrzeuge, Berlin, 2017.

[22] Technische Universität Berlin and Berliner Stadtreinigungsbetriebe, Gesamtkonzept für die Elektrifizierung von Entsorgungsverkehr, 2015. offentlichem Bus- und

[23] R. Ewert, A. Grahle, K. Martins-Turner, A. Syré, K. NAge and D. Göhlich, "Electrification of Urban Waste Collection: Introducing a Simulation-Based Methodology for Feasibility, Impact and Cost Analysis," in TRB Annual Meeting, Washington DC, 2020

[24] K. Nagel, R. Ewert, J. Bischoff, M. Maciejewski and A Grahle, "Dekarbonisierung des urbanen Verkehrs," 2020 [Online]. Available: https://svn.vsp.tuberlin.de/repos/public-svn/publications/vspwp/2020/2005/Dekarbonisierung_des_urbanen_Verkehrs-2020-0226.pdf. [Accessed 2104 2020].

[25] O. Erdinç, K. Yetilmezsoy, A. K. Erenoğlu and O. Erdinç, "Route optimization of an electric garbage truck fleet for sustainable environmental and energy management," Journal of Cleaner Production, vol. 234, pp. 1275-1286, 2019.

[26] J. Stender, "Hybrid-Müllwagen rollt leise zum Test durch Gelsenkirchen,” Funke Mediengruppe, 2017.

[27] I. Höltmann, "Berliner BSR - Was kostet eigentlich ein Müllwagen,” Berlin.

[28] Thinkstep Prognos, "Nullemissionsnutzfahrzeuge: Vom ökologischen Hoffnungsträger zur ökonomischen Alternativ," [Online]. Available: https://www.emobilsw.de/fileadmin/media/emobilbw/Publikationen/Studien/NFZ-Studie.pdf.

[29] Y. Zhao and O. Tatari, "Carbon and energy footprints of refuse collection trucks: a hybrid life cycle evaluation," Sustainable Production and Consumption, pp. 180-192, 2017

[30] I. Marrev, J. Becker and D. U. Sauer, "Battery dimensioning and life-cycle costs analysis for a heavy-duty truck considering the requirements of long-haul transportation," Energies, vol. 11, 2018

[31] T. Earl, L. Mathieu, S. Cornelius, S. Kenny, C. C. Ambel and J. Nix, "Analysis of long-haul battery electric trucks in EU Marketplace and technology, economic, environmental and policy perspectives," European Federation for Transport and Environment, pp. 17-18, 2018. 
[32] O. Wysocki, T. Zajdziński, J. Czyzewicz and J. Kropiwnicki, "Evaluation of the efficiency of the duty cycle of refuse collection vehicle based on real-world data," IOP Conference Series: Materials Science and Engineering, vol. 421, no. 4, 2018.

[33] A. Karle, Elektromobilität, Carl-Hanser Verlag, 2018, pp. 109-141.

[34] C. Heyn, Interviewee, Volvo Trucks. [Interview]. 28042020.

[35] J. Linssen, S. Bickert, W. Hennings, A. Schulz, S. Marker, P. Waldowski, V. Schindler, S. Mischinger, A. Schmid, E. Abbasi, K. Strunz, H. Maas, P. Schmitz, C. Günther, B. Schott, M. Danzer and O. Weinmann, Netzintegration von Fahrzeugen mit elektrifizierten Antriebssystemen in bestehende und zukünftige EnergieversorgungsstrukturenAdvances in Systems, 2012, p. 266.

[36] Volvo Trucks, Fact sheet Engine D8K320.

[37] Thunder Sky Winston, Operator's Manual LYP/LTHP/LP Thunder Sky Winston Rare-earth Lithium Power Battery.

[38] L. Taube, F. Schmid, A. Pasemann, J. Rieck, T. Heinrich, R. Reinking and F. Behrendt, "Contribution of Waste Management Companies towards a Flexible Energy System Using Sector Coupling," in Proceedings International ETGCongress 2019, Esslingen, VDE, 2019.

[39] O. Tremblay, L.-A. Dessaint and A.-I. Dekkiche, "A Generic Battery Model for the Dynamic Simulation of Hybrid Electric Vehicles," 2007 IEEE Vehicle Power and Propulsion Conference, 2008.

[40] R. B. Carlson, D. Scoffield and B. Bennett, "Results from the Operational Testing of the General Electric Smart Grid Capable Electric Vehicle Supply Equipment (EVSE)," no. December, 2013.

[41] M. Kwon, S. Jung and S. Choi, "A high efficiency bidirectional EV charger with seamless mode transfer for V2G and V2H application," IEEE Energy Conversion Congress and Exposition, ECCE, pp. 5394-5399, 2015.

[42] A. Genovese, F. Ortenzi and C. Villante, "On the energy efficiency of quick DC vehicle battery charging," World Electric Vehicle Journal, vol. 7, pp. 570-576, 2015.

[43] M. Landau, J. Prior, R. Gaber, M. Scheibe, R. Marklein and J. Kirchhof, "Technische Begleitforschung Allianz Elektromobilität - TEBALE Abschlussbericht,” p. 143, 2016.

[44] N. ChristofIdes, Worst-case Analysis of a new heuristic for the Traveling Salesmen Problem, Pittsburg: Management Sciences Research Group, Carnegle-Melloa University, 1976.

[45] O. Bräysy and M. Gendreau, "Vehicle Routing Problem with Time Windows, Part I: Route Construction and Local Search Algorithms," Transportation Science, p. 104-118, February 2005.

[46] O. Bräysy and M. Gendreau, "Vehicle Routing Problem With Time Windows, Part II: Metaheuristics," Transportation Science, February 2005.

[47] "VROOM Project," [Online]. Available: https://github.com/VROOM-Project/. [Accessed $28 \quad 04$ 2020].

[48] M. Tutuianu, A. Marotta, H. Steven, E. Ericsson, T. Haniu, N. Ichikawa and H. Ishii, "Development of a World-wide Worldwide harmonized Light duty driving Test Cycle," Technical Report, vol. 03, no. January, pp. 7-10, 2014.
[49] B. W. Baetz, "Modeling Municipal Solid Waste Collection Systems Using Derived Probability Distribution. I: Model Development," Journal of Environmental Engineering, November 2001.

[50] K. Lebeau, P. Lebeau, C. Macharis and J. Van Mierlo, "How expensive are electric vehicles? A total cost of ownership analysis.,"World Electric Vehicle Journal, p. 996, 2013.

[51] M. Wietschel, T. Gnann, P. Plötz and C. Doll, "Electric Trolley Trucks-A Techno-Economic Assessment for Germany," World Electric Vehicle Journal, November 2019.

[52] Bundesamt für Güterverkehr, "Förderung des Güterkraftverkehrs - Förderprogramm "EEN"," 2018.

[53] Q. De Clerck, T. van Lier, P. Lebeau, M. Messagie, L. Vanhaverbeke, C. Macharis and J. van Mierlo, "How Total is a Total Cost of Ownership?," World Electric Vehicle Journal, 2016.

[54] P. Kasten, "TCO verschiedener Energie- und Antriebskonzepte bei Pkw im Jahr 2030," in ENERGIETAGE 2017 - Die Energiewende im Verkehr effizient gestalten, Berlin, 2017.

[55] International Panel on Climate Change, 2006 IPCC Guidelines for National Greenhouse Gas Inventories, 2006.

[56] Umweltbundesamt, "CO2-Emissionsfaktoren für fossile Brennstoffe," Climate Change 27/16, 2016.

[57] L. Schwarz, Methodische Untersuchung und ganzheitliche Potentialbewertung zukünftiger Antriebssysteme zur CO2 Neutralität im Rennsport, Springer Vieweg, 2019.

[58] G. Boeing, “OSMnx: New methods for acquiring, constructing, analyzing, and visualizing complex street networks," Computers, Environment and Urban Systems, pp. 126-137, 2017.

[59] Die Bundesregierung, "Grundlage für CO2-Preis steht," December 2019. [Online]. Available: https://www.bundesregierung.de/bregde/themen/klimaschutz/nationaler-emissionshandel1684508. [Accessed 0405 2020].

[60] F. Pillau, "heise.de," [Online]. Available: https://www.heise.de/autos/artikel/Elektrisch-Abfallsammeln-Collect-26-E-4297122.html. [Accessed 11 Mai 2020]. 